\title{
Anonymous Questionnaire and Cotinine Test as Smoking Prevalence Screening
}

\author{
Tatyana I. Nikiforova ${ }^{1}$ and Maria V. Khandy ${ }^{2}$
}

\author{
${ }^{1}$ Children's Infectious Clinical Hospital, Yakutsk \\ ${ }^{2}$ M.K. Ammosov North-Eastern Federal University, Yakutsk \\ *Corresponding author. Email: mv.khandi@s-vfu.ru
}

\begin{abstract}
The article presents the prevalence of tobacco smoking based on the results of the anonymous questionnaire and cotinine test. Tobacco use is a major risk factor for a range of chronic diseases, including cancer, lung disease and cardiovascular disease. It has been proven that the respiratory system (larynx, trachea, bronchi, lungs) is more affected by regular nicotine intake. That is why almost every smoker has problems with the lungs, bronchi or trachea. The aim of the research was to study the prevalence of smoking among teenagers of Yakutsk according to two methods questionnaire and cotinine test. The study was conducted on a representative sample of schoolchildren in Yakutsk using a random number generator, 5 schools were selected from the list of all secondary schools. 931 in 8-11 grades between the ages of 13 and 17 years old were invited to participate voluntarily in the questionnaire. Boys were $57.3 \%$, girls $-42.7 \%$. The prevalence of tobacco smoking among adolescents 13-17 years old in the Republic of Sakha (Yakutia) according to the rapid test for cotinin, the definition of carbon monoxide was $33.6 \%$ (among boys $31.2 \%$, among girls $37.0 \%$ ). This is significantly (2.5 times) higher than the anonymous questionnaire. We need Integrative approaches, combining both preventive and special programs using age-appropriate modern rehabilitation methods to prevent smoking among teenagers.
\end{abstract}

Keywords: cotinine test, smoking prevalence, screening, anonymous questionnaire, Sakha, Yakutia

\section{INTRODUCTION}

\subsection{Tobacco smoking as a medical and social problem}

Tobacco appeared $6,000 \mathrm{BC}$ and from the very beginning it accompanied humanity like 'tea and food'. Tobacco is a crop known to the ancient civilizations of Central and South America, as well as the Middle East and China. It reached Europe as late as the 15th century, and the first person who brought the tobacco seeds to Spain in October 1492 was a participant of the second trip by Christopher Columbus, a monk called Romano Paro. Tobacco appeared in Russia at the very beginning of the 17 th century [1].

According to the World Health Organization (WHO), tobacco smoking annually claims almost 7 million human lives, about a million of which are passive smokers. [2] According to many authors, tobacco use among children and teenagers worldwide has increased in recent years [3].

The influence of tobacco smoke is especially affected by children and teenagers due to the functional and physiological features of the growing body, so this problem is very relevant in pediatrics. According to domestic authors, in the Russian Federation over the past decade, the number of diseases associated with tobacco smoking has increased [2].

Regardless of the number of tobacco products smoked per day, smoking children represent a special risk group, where health deviations may begin to appear by school graduation, which may lead to a decrease in the quality of life and loss of efficiency in the future [5].

According to WHO, the average prevalence of tobacco use among adolescents in Europe for 2013-14 
was $12 \%$ for boys and $11 \%$ for girls. According to the materials of the Federal State Statistics Service for 2018, the prevalence of smoking among teenagers of 15 years and older in Russia is $11 \%$ [3].

The prevalence of tobacco smoking in Russia varies by region. According to the results of selective sociological studies, smoking among schoolchildren ranges from 20 to $40 \%[6,7]$.

The Republic of Sakha (Yakutia) is characterized by an extreme continental climate with significant daily and annual fluctuations in ambient temperature, reaching up to 1000 . Winter lasts 6-7 months, cold, dry and windless weather prevails at this time of the year. A feature of the winter climate of Yakutia are thick fog formed by low temperature, low mobility of the surrounding air, insufficient solar activity, exhaled moisture by people and animals, exhaust gases, smoke from furnaces. In connection with the climatoecological characteristics of the Republic of Sakha (Yakutia), children are in a room for a long time where there is a large accumulation of people, including smokers, which creates conditions for passive smoking [3], which poses a special threat to the child's body significantly increasing the risk of developing a number of diseases of childhood [8-10].

\subsection{Methods for studying the prevalence of tobacco smoking}

The most popular methods of studying the prevalence of tobacco smoking are questionnaire and cotinine test.

A questionnaire is a procedure for a written survey. It is one of the methods of quantitative research in marketing and sociology. The questionnaire information collection method is preferred when it is necessary to collect certain data in a short time period [3].

Anonymous questionnaires have a number of advantages over other types of information collection. Data obtained in an anonymous way are independent, the result is fast enough, simple to analyze, systematize and evaluate. When studying the prevalence of smoking, both domestic and foreign researchers often use this technique [11-13].

Many researchers, using the questionnaire also use the immunochromatographic express test for cotinin to quick and qualitative cotinin detection. Cotinine is a metabolite of nicotine and is a biomarker of tobacco smoke exposure. The presence of cotinine can be detected in different biological materials. Cotinine can persist and detected for 36-48 hours after smoking the last cigarette in urine even after smoking cessation $[14,4]$.

The cotinine express test is a fast, qualitative, reliable method of determining the nicotine-cotinine metabolite in vitro by using a special immunochromatographic test strip. The sensitivity of the test corresponds to $200 \mathrm{ng} / \mathrm{ml}$ cotinine, the validity of the method is $99.9 \%[11,12]$.

Passive smoking can also be reflected in the results of the analysis. If the child is indoors with a daily smoker, then the analysis in this child may be positive.

The advantage of a cotinin test over an anonymous questionnaire is that even if respondents in the questionnaire give a false answer and hide the fact of smoking, then the test will show a reliable result.

The purpose of the present research was to study the prevalence of smoking among teenagers of Yakutsk by anonymous questionnaire and cotinine test.

\section{MATERIALS AND METHODS}

The study was conducted on a representative sample of schoolchildren in Yakutsk, 5 schools were selected from the list of all secondary schools of the city by a random number generator (No. 14, 18, 27, 28, 31). Students in 8-11 grades were invited to voluntarily participate in the study. The anonymous questionnaire involved 931 people aged from 13 to 17 years old. A modified version of the global questionnaire screening proposed by WHO to estimate the prevalence of tobacco smoking among adolescents was used for the study.

\section{RESULTS AND DISCUSSION}

The gender and age structure of respondents is presented in Table 1. There were more boys than girls (57.3\% and $42.7 \%$, respectively), but age structures were not statistically significantly different.

Table 1. Structure of interviewed teenagers in Yakutsk by age and gender, n (\%)

\begin{tabular}{|l|l|l|l|}
\hline Groups & $n$ & $13-14$ y.o & $15-17$ y.o \\
\hline Boys & 533 & $220(41.3)$ & $313(58.7)$ \\
\hline Girls & 398 & $163(41)$ & $235(59)$ \\
\hline Both genders & 931 & $383(41.1)$ & $548(58.9)$ \\
\hline
\end{tabular}

The prevalence of smoking among 13-17 years old schoolchildren according to the questionnaire was $13.5 \%, 4 \%$ of which of all children smoked daily, $9.6 \%$ of children sporadically. The prevalence of smoking among boys and girls was comparable (Table 2).

In the 15-17 age group, the proportion of smokers was statistically significantly higher $(19.4 \%$, including daily smokers $5.7 \%$, occasional smokers $13.7 \%$ ) than in the $13-14$ age group $(5.2 \%$, including daily smokers $1.6 \%$, occasional smokers $3.6 \%(\mathrm{p}<0.05))$. 
Table 2. Smoking status of 13-17 years old schoolchildren according to anonymous questionnaire

\begin{tabular}{|c|c|c|c|c|c|c|}
\hline Smoking rate & \multicolumn{2}{|l|}{$\begin{array}{l}13-14 \text { years } \\
n(\%)\end{array}$} & \multicolumn{2}{|l|}{$\begin{array}{l}15-17 \text { years } \\
n(\%)\end{array}$} & \multicolumn{2}{|l|}{$\begin{array}{l}\text { 13-17 years } \\
n(\%)\end{array}$} \\
\hline Boys & \multicolumn{2}{|l|}{220} & \multicolumn{2}{|l|}{313} & \multicolumn{2}{|l|}{533} \\
\hline daily & $2(0.9)$ & \multirow[t]{2}{*}{$8(3,6)$} & $15(4.8)^{\star}$ & \multirow[t]{2}{*}{$53(16,9)^{\star}$} & $17(3.2)$ & \multirow[t]{2}{*}{$61(11.5)$} \\
\hline episodes & $6(2.7)$ & & $38(12.1)^{\star}$ & & $44(8.3)$ & \\
\hline do not smoke & \multicolumn{2}{|l|}{$212(96.4)$} & \multicolumn{2}{|l|}{$260(83.1)$} & \multicolumn{2}{|l|}{472 (88.5) } \\
\hline Girls & \multicolumn{2}{|l|}{163} & \multicolumn{2}{|l|}{235} & \multicolumn{2}{|l|}{398} \\
\hline daily & $4(2.5)$ & \multirow[t]{2}{*}{$12(7.4)$} & $16(6.8)^{\star}$ & \multirow[t]{2}{*}{$53(22.5)^{\star}$} & $20(5.0)$ & \multirow[t]{2}{*}{65 (16.3) } \\
\hline episodes & $8(4.9)$ & & $37(15.7)^{\star}$ & & 45 (11.3) & \\
\hline do not smoke & \multicolumn{2}{|l|}{151 (92.6) } & \multicolumn{2}{|l|}{$182(77.5)$} & \multicolumn{2}{|l|}{333 (83.7) } \\
\hline In total & \multicolumn{2}{|l|}{383} & \multicolumn{2}{|l|}{548} & \multicolumn{2}{|l|}{931} \\
\hline daily & $6(1.6)$ & \multirow[t]{2}{*}{$20(5.2)$} & $31(5.7)^{\star}$ & \multirow[t]{2}{*}{$106(19.4)^{\star}$} & $37(4.0)$ & \multirow[t]{2}{*}{$126(13.5)$} \\
\hline episodes & $14(3.6)$ & & $75(13.7)^{\star}$ & & $89(9.6)$ & \\
\hline do not smoke & \multicolumn{2}{|l|}{363 (94.8) } & \multicolumn{2}{|l|}{442 (80.6) } & \multicolumn{2}{|l|}{805 (86.4) } \\
\hline
\end{tabular}

$* \mathrm{p}<0.05$ when compared with a group of 13-14 years old

The debut of tobacco smoking in $1.8 \%$ was at the age of 8-10 years old, in $60.3 \%-11-12$ years old, in $22.7 \%-13-14$ years old, in $15.2 \%-15-17$ years old.

13-14 years old Boys had experience with an average of $15.0 \pm 2.0$ months., Girls of the same age group $-9.3 \pm 1.0$ months. Among boys $15-17$ years old $-18.0 \pm 18.0$ months., Among girls $-15.0 \pm 10.0$ months.

The question "How many cigarettes have you smoked in your life?" the smoking teenagers answered as follows:

- up to 10 cigarettes $-5.6 \%$,

- up to 50 cigarettes $-25.4 \%$,

- up to 100 cigarettes $-40.5 \%$,

- 100 and over cigarettes $-28.5 \%$.

13-17 years old Schoolchildren answered to the question "How do you usually get cigarettes?" as follows:

- buy in the shop - $12.7 \%$

- Buy in the machine - 0

- Take from friend or brother $-35.7 \%$

- Take from parents $-19.0 \%$

- Ask a friend to buy him/her a cigarette - $32.6 \%$

Schoolchildren were given an immunochromatographic express test with anonymous questionnaire, for the determination of cotinine in urine. The express test for cotinin turned out to be positive in $33.6 \%$ of the examined 13-17 years old schoolchildren. There were no significant differences between boys and girls. In contrast to the questionnaire data, the prevalence of smoking according to the cotinine express test was statistically significantly higher in the group of 13-14 years old compared to the group of 15-17 years old (48.3\% versus $23.4 \%,(\mathrm{p}<0.05)$ (Table 3$)$.

Comparison of tobacco prevalence data from the results of two screening methods is shown in fig. 1 . According to the results of the immunochromatographic rapid test for the determination of cotinine in urine, the proportion of children smoking increased by 2.5 times compared to the data on the results of the questionnaire. Among boys, tobacco use increased by $19.7 \%$ and among girls by $20.7 \%$.

Table 3. Cotinin test result by age and gender of 13-17 years old schoolchildren

\begin{tabular}{|l|l|l|l|}
\hline $\begin{array}{l}\text { Cotinine test } \\
\text { result }\end{array}$ & $\begin{array}{l}13-14 \text { y.o } \\
n(\%)\end{array}$ & $\begin{array}{l}15-17 \text { y.o } \\
n(\%)\end{array}$ & $\begin{array}{l}13-17 \text { y.o } \\
n(\%)\end{array}$ \\
\hline Boys & 220 & 313 & 533 \\
\hline Negative & $123(55.9)$ & $244(77.9)$ & $367(68.8)$ \\
\hline Positive & $97(44.1)^{\star}$ & $69(22.1)$ & $166(31.2)$ \\
\hline Girls & 163 & 235 & 398 \\
\hline Negative & $75(46.0)$ & $176(74.8)$ & $251(63.0)$ \\
\hline Positive & $88(54.0)^{\star}$ & $59(25.2)$ & $147(37.0)$ \\
\hline In total & 383 & 548 & 931 \\
\hline Negative & $198(51.7)$ & $420(76.6)$ & $618(66.4)$ \\
\hline Positive & $185(48.3)^{\star}$ & $128(23.4)$ & $313(33.6)$ \\
\hline
\end{tabular}

*p $<0.05$ when compared with a group of $15-17$ years old 


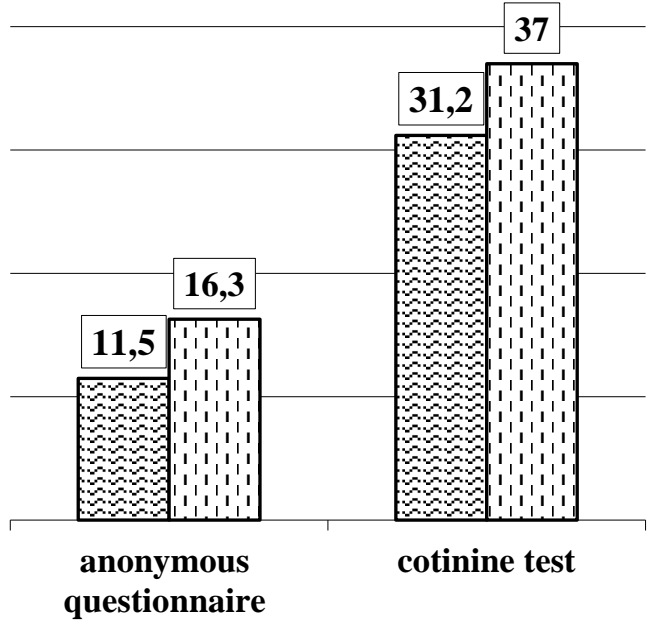

国boys

Figure 1. Relative number of 13-17 years old schoolchildren smoking according to anonymous questionnaire and express test for cotinin by gender $(\%)$

When comparing groups according to the results of screening for tobacco smoking for 13-17 years old schoolchildren, it turned out that according to the results of the express test, the number of schoolchildren smoking significantly increased. Among girls of 13-14 years old, the number of smokers increased by $46.6 \%$, among girls of $15-17$ years old - by $2.6 \%$. Among boys 13-14 years old, the number of smokers increased by $40.5 \%$, in the group of 15-17 years old - by $5.2 \%$ (Figure 2).

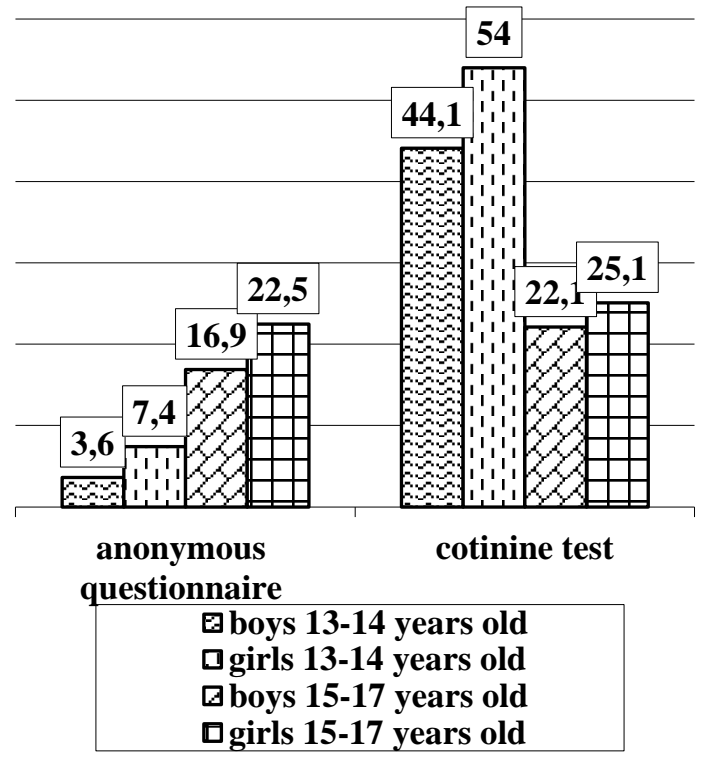

Figure 2. Comparison of the distribution of 13-17 years oldschoolchildren groups according to the anonymous questionnaire of the express test for cotinin, (\%)

\section{CONCLUSION}

Smoking, being a risk factor for human health, leads to the development of various diseases of the cardiovascular, respiratory and other systems of the body, and as a result is the cause of increased mortality of the population from nicotine-dependent diseases. Analysis of researches showed that tobacco smoking referred to exogenous risk factors for respiratory diseases. Respiratory organs are the first system affected by tobacco smoke, so smoking makes a significant contribution to the pathogenesis of diseases of the respiratory system. The influence of tobacco smoke is especially affected by children and teenagers due to the functional and physiological features of a growing body, which determines the special relevance of tobacco smoking problems in pediatric practice. According to Russian authors, the number of diseases associated with tobacco smoking has been growing in the Russian Federation over the past decade. E-cigarettes and smokeless use of nicotine-containing substances have also been very popular in recent years. Introduction and addiction occurs in childhood. A young, growing body is more susceptible to the influence of adverse factors, which should be taken into account when using tobacco prevention programs. Tobacco smoking remains the main single cause of premature death worldwide.

Banning demonstrations of tobacco products at point of sale and making display of health warnings on packaging mandatory are particularly effective in reducing tobacco's attractiveness to young people. Tobacco packs in the Russian Federation display warnings such as: "Smoking causes heart attacks and strokes", "Smoking is a cause of lung cancer", "Protect children from tobacco smoke" and "Smoking increases the risk of death from heart and lung diseases". The Russian Federation acceded to the WHO Framework Convention on Tobacco Control in 2008. The 2013 federal law reflects the Convention's measures, including banning advertising and promotion of tobacco and discounts on products, and preventing demonstration of tobacco products and the process of use in newly created TV broadcasts and films. Tobaccosmoking is banned in defined public places (such as education, cultural and sports facilities and their environs, youth affairs institutions, children's playgrounds and beaches). Price and tax measures have been introduced to decrease demand (minimum retail prices, for example, are set at $75 \%$ of maximum retail prices) and significant steps have been taken to raise public awareness about the harms of smoking and second-hand tobacco smoke.

There are several types of screening study of the prevalence of tobacco smoking. The most popular of them is the questionnaire method. Anonymous questionnaires have a number of advantages over other types of information collection. It is independent, data 
by anonymous questionnaires are simply analyzed, systematized and evaluated. However, as it turned out, the questionnaire method does not reflect the objective prevalence of tobacco smoking. Another popular screening method is the urinary cotinine rapid test. The technique is simple, does not require special training, reliable and fast. Carbon monoxide in exhaled air was determined to confirm smoking. All these techniques were applied in the study.

The cotinine test does not distinguish between active and passive smokers, as well as the use of nicotine in other forms (chewing forms, sniffing mixtures, etc.). In this study, the questionnaire did not determine the prevalence of passive smoking and nicotine use in other species among schoolchildren. Despite the fact that the questionnaire was anonymous, some of the children probably concealed the fact of smoking and/or were subjected to passive smoking, which could affect the results of the express cotinine test.

Thus, children and teenagers may hide the fact of cigarette smoking or nicotine use in other forms to establish the prevalence of tobacco smoking and nicotine-containing products, it is preferable to screen with an express test to determine cotinine in the urine.

\section{REFERENCES}

[1] M. Sikorska-Jaroszyńska, M. Mielnik-Błaszczak, Passive smoking as an environmental health risk factor, Ann. Agric. Environ. Med. 19(3) (2012) 547-550.

[2] Yu.V. Mikhailova, M.M. Lisitsyna, I.B. Shikina, Soc. aspects of health populat. 5 (2017).

[3] T.I. Nikiforova, I.V. Ozerskaya, N.A. Geppe et al., Rus. Bull. of pediatr. 4 (2020) 94-100.

[4] M. Raja, A. Garg, P. Yadav et al., Clin. Diagn. Res. 10(3) (2016) ZE04-ZE6.

[5] Yu.N. Krasnova, Siber. Med. J. 6 (2015) 11-16.

[6] G.M. Sakharova, N.S. Antonov, O.O. Semagay, Pulmonol. 2 (2017) 79-186.

[7] Yu.N. Krasnova, Siber. Med. J. 6 (2015) 11-16.

[8] J. Almirall, Comm. Acquired Inf. 2 (2015) 32-37.

[9] A. Batscheider, S. Zakrzewska, J. Heinrich, C.M. Teuner et al., BMC Health Serv. Res. 12 (2012) 344.

[10] H.J. Małgorzata, M. Sikorska-Jaroszyńska, D. Mielnik-Błaszczak et al., Ann. of Agricult. and Environ. Med. 19(3) (2012) 547-550.

[11] Yu.E. Mazur, N.A. Ilyenkova, V.V. Chikunov et al., Sib. honey. Rev. 5 (2013) 56-57.
[12] N.A. Ilyenkova, Yu. Mazur, Vopr. Let's lie. Ped. 10(5) (2011) 5-8.

[13] J. Britton, Practitioner 5 (2010) 54.

[14] B.Ts. Batozhargalova, Yu.L. Mizernitsky, Sib. Honey. Rev. 4, (2012) 45-50. 